\title{
Quality Management System Implementation in Certified Children's Toy Industries: The Level of Application, Motives, and Constraints
}

\author{
Muhammad Imron Rosyidi ${ }^{1,2^{*}}$, Maria Theresia Sri Budiastuti ${ }^{3}$, Mugi Rahardjo ${ }^{4}$,
}

Totok Gunawan ${ }^{5}$

\author{
${ }^{1}$ Doctoral Program in Environmental Science, Universitas Sebelas Maret, Surakarta 57126, Indonesia. \\ ${ }^{2}$ Department of Industrial Engineering, Universitas Muhammadiyah Magelang. Magelang 56172, Indonesia. \\ ${ }^{3}$ Faculty of Agriculture, Universitas Sebelas Maret, Surakarta 57126, Indonesia. \\ ${ }^{4}$ Department of Economic Development, Universitas Sebelas Maret, Surakarta 57126, Indonesia. \\ ${ }^{5}$ Faculty of Geography, Universitas Gadjah Mada, Yogyakarta 55281, Indonesia. \\ *Corresponding author.Email: m_imron_rosyidi@ummgl.ac.id
}

\begin{abstract}
This study was designed to measure at which level the quality management system (QMS) had been implemented in the children's toy industries with SNI-certified products (SNI=Indonesian National Standard) in Yogyakarta, Indonesia. SNI certificates are granted only if a company has applied QSM based on ISO 9001. The analysis also observed the company's motives and constraints in QMS realization using the case study of four SNI-certified children's toy companies from the existing 21 toy enterprises in the area. The results showed that the level of internal QSM implementation in small-scale toy industries was poor but fairly good among the medium-scale companies. The medium-scale industries can apply QMS better than the smallscale ones because they have established a department responsible for actualizing the quality system. These industries employed QMS due to various motivations, including to improve product quality, operational time, and QMS and to reduce the number of product defects. Nevertheless, they also had to overcome one particular constraint, that is, the costs of QMS implementation add to the financial responsibility of the companies.
\end{abstract}

Keywords: QMS, toy industries, application, motives, constraint

\section{INTRODUCTION}

The implementation of a quality management system (QMS) based on ISO 9001 has a significant influence on certified companies. Previous studies have proven that by applying QMS, a certified company can successfully improve its quality system, customer satisfaction, and company image [1] and that motivation to receive certificates positively correlates with the effectiveness of ISO 9001 implementation [2]. In Indonesia, children's toy industries are obligated to apply product standards through the Indonesian National Standard (SNI) certification. This SNI certification is a guarantee of quality and requirements for the final products. To receive product certification, the owner of the company needs to have implemented QMS (BSN, 2009). For instance, the standards for QMS in toy industries are according to ISO 9001. Several studies have shown that QMS is a useful tool to ensure the quality and competitiveness of the company [3], improve management and work efficiency [4], and operational performance [5]; [2]. The adoption of ISO 9001 for QMS can improve the production process in the company [6]. Companies that have successfully applied ISO 9001-based QMS are known to achieve improvements in product quality, operational performance, and business [7]; [8], as well as quality management [9]. QMS can also show that quality can be created, controlled, and improved through standard procedures [10].

The company's motives to receive certification by applying ISO 9001-based QMS are caused by internal and external reasons [11]. Internal reasons are the willingness to improve processes or procedures, while external reasons are related to pressures, demands, and incentives [12];[13]. Applying standard processes through QMS encourages companies to reduce human errors during the work [14]. For companies, being certified means effective management and control over day-to-day activities [15], as well as wider access to market [16] or, in other words, an opportunity to build and open new markets for their standard-compliant products.

The application of QMS in the company is not without obstacles. Internalizing ISO 9001-based QMS requires transformation and transfer of knowledge, which are not easy. QMS can be transformed internally through two practices: (1) education on standards for the employees and (2) improvement of production processes conforming to the documented standards [17]. For some companies, the limitations and capabilities of human resources and financial conditions can create a significant obstacle to the application of a standard [18], meaning that these companies require more time to implement it effectively. 
Training for any staff involved in the standardization process is inevitable as it is a form of human resource management. It is essential because this process focuses on not only technical matters but most importantly strategy [16]. Issues of technical gaps, government regulations, awareness and access to information, and financial access also constrain companies from adopting sustainable standards properly [18].

Previous research has identified many motives for and conditions during the internal implementation of QMS in a company, and some of the findings are surprising. The quality of internal QMS implementation in certified companies is insignificant, and the QMS elements are applied minimally [19];[15]. In response to this, the effectiveness of QMS implementation among certified companies needs to be measured by the management parties to achieve necessary enhancement [20]. This study was intended to identify the application of QMS in SNI-certified children's toy industries as a prerequisite for receiving the certification of SNI product and then to explain the motives for and constraints in QMS implementation.

\section{METHODOLOGY}

This research is a case study of SNI-certified children's toy industries. It employed a quantitative research approach to obtain information on QMS implementation within the enterprises (internally). A search through the toy companies in the Special Region of Yogyakarta resulted in 21 industries with various types of toy products. Only four of them had SNI-certified products.

The questionnaire instrument was developed and tested in a pilot study, then carefully revised and improved to obtain a validated questionnaire instrument. It contains questions formulated based on information, literature reviews, and previous research. This questionnaire is divided into three parts, namely (1) a checklist to measure the application of clauses in ISO 9001-QMS in the company, (2) a questionnaire on the company's motives to apply QMS, and (3) a questionnaire on the constraints in QMS implementation

The questionnaire was distributed to the four children's toy industries that had SNI certified products and had applied the ISO 9001-based QMS as a condition for obtaining the SNI certification for their final products. Among the four companies, three of them represented small-scale industries, and one was classified as medium-scale. This industrial classification was based on the Regulation of the Indonesian Minister of Industry No. 64/M-INDPER/7/2016. The questionnaire was given to personnel who had a role in implementing QMS internally, namely company owners, production departments, and quality control departments. Afterward, the data obtained from this questionnaire survey was processed statistically in SPSS v.18.

The assessment criteria for QMS application were based on the availability of QMS procedures in the company, the availability of quality documents, and their use in the company. For this study, the last criterion is differentiated into not implemented, minimally implemented, not fully implemented, and fully implemented.

\section{RESULTS AND DISCUSSION}

There are four children's toy industries that have SNIcertified products in the Special Region of Yogyakarta. Each has a different classification according to the number of workers, investment values, the length of time the company has held the product certificate, and the source of costs for certifying their products. Three of the four companies had certified their products during the government's facilitation program and one industry had proceeded its product certification at the company's expense (see Table 1).

Table 1 The characteristics of selected children's toy industries with SNI-certified products

\begin{tabular}{|cccccc|}
\hline SMEs & Types of Products & Workers & $\begin{array}{c}\text { Investment } \\
\text { Values }\end{array}$ & $\begin{array}{c}\text { Length of Holding } \\
\text { Product Certificates }\end{array}$ & Sources \\
\hline A & Educational teaching aids & 15 & $<1$ billion & 4 years & Facilitation \\
\hline B & Educational teaching aids & 10 & $<1$ billion & 4 years & Facilitation \\
\hline C & Educational teaching aids & 12 & $<1$ billion & 4 years & Facilitation \\
\hline D & Educational teaching aids & 27 & $1-15$ billion & 6 years & Independent funding \\
\hline
\end{tabular}

\subsection{Quality Management System Implementation in Children's Toy Industries}

Table 2 shows the level of QMS implementation in the four toy enterprises analysed in this study. These results were obtained from the questionnaires given to company owners, heads of the production department, and heads of the quality control department. They were asked to provide information and answers reflecting the state of the company during the implementation of "the clause procedures of ISO 9001-based QMS", "the availability of quality documents", and "conditions during implementation". 
Table 2 The level of QMS implementation in children's toy industries

\begin{tabular}{|clrl|}
\hline SMEs & \multicolumn{1}{c}{ Clauses } & $\begin{array}{c}\text { Percentage of } \\
\text { application }\end{array}$ & Categories \\
\hline \multirow{3}{*}{ A } & Clause 4: Quality Management System & $37.78 \%$ & Bad \\
& Clause 5: Management Responsibility & $40.00 \%$ & Medium \\
& Clause 6: Resource Management & $40.00 \%$ & Medium \\
& Clause 7: Product Realization & $38.18 \%$ & Bad \\
& Clause 8: Measurement, Analysis, and Improvement & $32.00 \%$ & Bad \\
\hline \multirow{4}{*}{ B } & Clause 4: Quality Management System & $35.56 \%$ & Bad \\
& Clause 5: Management Responsibility & $37.78 \%$ & Bad \\
& Clause 6: Resource Management & $40.00 \%$ & Medium \\
& Clause 7: Product Realization & $36.36 \%$ & Bad \\
& Clause 8: Measurement, Analysis, and Improvement & $30.00 \%$ & Bad \\
\hline \multirow{4}{*}{ C } & Clause 4: Quality Management System & $37.77 \%$ & Bad \\
& Clause 5: Management Responsibility & $33.33 \%$ & Bad \\
& Clause 6: Resource Management & $36.00 \%$ & Bad \\
& Clause 7: Product Realization & $34.55 \%$ & Bad \\
& Clause 8: Measurement, Analysis, and Improvement & $32.00 \%$ & Bad \\
\hline \multirow{2}{*}{ D } & Clause 4: Quality Management System & $89.62 \%$ & Very good \\
& Clause 5: Management Responsibility & $97.77 \%$ & Very good \\
& Clause 6: Resource Management & $92.00 \%$ & Very good \\
& Clause 7: Product Realization & $95.76 \%$ & Very good \\
& Clause 8: Measurement, Analysis, and Improvement & $92.66 \%$ & Very good \\
\hline
\end{tabular}

The assessment results of the QMS implementation were categorized into a rating scale, namely "Very bad = level of implementation $<20 \%$ ", "Bad $=20 \% \leq$ level of implementation $<40 \%$ ", "Medium $=40 \% \leq$ level of implementation $\leq 60 \%$ ", "Good $=60 \% \leq$ level of implementation $\leq 80 \%$ ", "Very good $=80 \% \leq$ level of implementation $\leq 100 \%$ ".

Table 3 The internal motives of small-scale industries to implement QMS

\begin{tabular}{|c|c|c|c|}
\hline Company's motives & Means & Modes & Std. Deviations \\
\hline Increased product/service quality & 4.33 & 4 & 0.577 \\
\hline More efficient operational time & 4.33 & 4 & 0.577 \\
\hline Improvement in the quality management system & 4.33 & 4 & 0.577 \\
\hline A decrease in the number of incompatible products/defects & 4.33 & 4 & 0.577 \\
\hline Improvement in internal process and procedure & 4.00 & 4 & 0.000 \\
\hline Company's decision /commitment & 4.00 & 4 & 0.000 \\
\hline A rise in profits & 4.00 & 4 & 0.000 \\
\hline Reduced operational costs & 3.67 & 4 & 0.577 \\
\hline
\end{tabular}

Table 4 The internal motives of medium-scale industries to implement QMS

\begin{tabular}{|c|c|c|c|}
\hline Company's motives & Means & Modes & Std. Deviations \\
\hline Company's decision/commitment & 5.00 & 5 & 0.000 \\
\hline A decrease in the number of incompatible products/defects & 5.00 & 5 & 0.000 \\
\hline Improvement in quality management system & 5.00 & 5 & 0.000 \\
\hline Increased product/service quality & 5.00 & 5 & 0.000 \\
\hline Improvement in internal process and procedure & 4.67 & 5 & 0.577 \\
\hline More efficient operational time & 4.67 & 5 & 0.577 \\
\hline A rise in profits & 4.00 & 4 & 0.000 \\
\hline Reduced operational costs & 4.00 & 4 & 0.000 \\
\hline
\end{tabular}

Tables 3 and 4 show similarities between the internal motivations of the small and medium-scale toy industries to apply QMS. The similar motives were to improve product quality, efficient operational time, and quality management system and to reduce the number of defects. However, the primary internal motivation of medium-scale toy enterprises to implement QMS was the company's decision or commitment. 
Table 5 The external motives of small-scale industries to implement QMS

\begin{tabular}{|lccc|}
\hline \multicolumn{1}{c}{ Company's motives } & Means & Modes & Std. Deviations \\
\hline Government's facilitation & 4.33 & 4 & 0.577 \\
A response to government's requirements & 4.33 & 4 & 0.577 \\
An effort to maintain and increase product competitiveness & 4.00 & 4 & 0.000 \\
Company image enhancement & 4.00 & 4 & 0.000 \\
Fulfilment of requirements in business transactions & 3.67 & 4 & 0.577 \\
Request or pressure from customers & 3.33 & 3 & 0.577 \\
Market regulation pressures & 3.33 & 3 & 0.000 \\
A promotion strategy & 3.00 & 3 & 0.000 \\
\hline
\end{tabular}

Table 6 The external motives of medium-scale industries to implement QMS

\begin{tabular}{|lccc|}
\hline \multicolumn{1}{|c}{ Company's motives } & Means & Modes & Std. Deviations \\
\hline An effort to increase competitiveness & 5.00 & 5 & 0.000 \\
Company image enhancement & 5.00 & 5 & 0.000 \\
A response to government's requirements & 3.67 & 2 & 1.528 \\
Fulfilment of requirements in business transactions & 3.33 & 4 & 1.155 \\
A promotion strategy & 3.33 & 4 & 1.155 \\
Market regulation pressures & 3.33 & 4 & 1.155 \\
Government's facilitation & 2.67 & 1 & 1.528 \\
Request or pressure from customers & 2.00 & 1 & 1.000 \\
\hline
\end{tabular}

Based on the respondents' answers, the external motives of small-scale toy industries to adopt QMS included the government's facilitation and the necessity to respond to the requirements that the government had set as the standards for children's toys (see Table 5). Meanwhile, for the medium-scale industries, the external motives were the potential for increasing competitiveness and company image (see Table 6).

Table 7 The constraints in QMS implementation in small-scale children's toy industries

\begin{tabular}{|lccc|}
\hline \multicolumn{1}{|c|}{ Constraints in QMS implementation } & Means & Std. Deviations & Ranks \\
\hline Costs of implementation and certification & 4.7500 & 0.43301 & 1 \\
Financial access & 3.9167 & 0.14434 & 2 \\
Company's awareness and access to information & 3.8333 & 0.38188 & 3 \\
Applicable regulations & 3.7633 & 0.51316 & 4 \\
Technical gaps & 3.6667 & 0.57735 & 5 \\
\hline \multicolumn{2}{l}{} \\
\hline
\end{tabular}

Table 8 The constraints in QMS implementation in medium-scale children's toy industries

\begin{tabular}{|lccc|}
\hline \multicolumn{1}{|c}{ Constraints in QMS implementation } & Means & Std. Deviations & Ranks \\
\hline Costs of implementation and certification & 3.9167 & 0.57735 & 1 \\
Technical gaps & 3.8900 & 0.19053 & 2 \\
Financial access & 3.2500 & 0.43301 & 3 \\
Company's awareness and access to information & 2.5833 & 0.28868 & 4 \\
Applicable regulations & 2.5567 & 0.76788 & 5 \\
\hline
\end{tabular}

The questionnaire survey found that the four industries faced similar obstacles in operating QMS, namely costs of implementation and certification. For the small-scale toy enterprises, the major constraint was the costs of implementation. Problems in financial access were deemed crucial in applying an effective QMS (see Tables 7 and 8).

\subsection{QMS Implementation in Children's Toy Industries with SNI-certified Products}

The Indonesian National Standard (SNI) Certification is a standard that nationally applies in Indonesia. Products that meet SNI requirements are granted with product certification. The quality management system (QMS) has been implemented internally in the four companies observed in this study as a condition to obtain product certification. Based on the assessment results, the application of QMS in three (3) children's toy industries with SNI-certified product fall into the category "bad" even though an effective QMS implementation is known to increase operational benefits and production process [8];[19];[6]. SNI-certified small-scale toy industries appear to have poor to moderately good QMS implementation ("Bad $=20 \% \leq$ level of implementation $<40 \%$ " and "Medium $=40 \% \leq$ level of implementation $\leq 60 \%$ "). This finding confirms that passing SNI certification does not necessarily correlate with the proper implementation of QMS in a company, which is in line with [19]. Although the company owners have a sufficient understanding of QMS and the 
benefits of its application, the limited number and educational level of the staff pose a significant challenge for the company's leaders in channelling the importance of standards to their employees. QMS has not been fully implemented in the company, meaning that no QMS documents are available.

On the contrary, the internal realization of QMS in the medium-scale children's toy industry is categorically very good because this company feels how QMS has successfully improved the product quality and company image to date. This company has appointed a management representative in charge of implementing the quality standards. It is consistent with [11], which explains that company size controls the perceived benefits of QMS implementation. The medium-scale toy industry can apply QMS well because its board of leaders is committed to using management system procedures and activity documentation for performance evaluation and communicate them to the employees. Previous research claims that an apparent attitude and commitment of leaders in the company can make QMS implementation run effectively [2].

This study has found the major reason behind poor internal QMS implementation in certified toy industries. These companies do not have units or people who handle standardization, and consequently, the standard practices and documented procedure implementation cannot be carried out both strategically and effectively. It is consistent with Blind (2016), who states that the existence of a standardization unit within a company promotes strategic actions to execute the regulations of said standardization. Documents and records of quality are not available, which marks the partial implementation of QMS in children's toy industries. In QMS, documentation is fundamental because the produced files are a work reference, evidence of application, and material for evaluation and planning of future activities; all of which enable continuous improvement. This argument is consistent with Cai (2017) who claims that documentation is a vital step in the process of QMS internalization. For better compliance with the standards, the companies need continuous improvement and involve all parties to gradually complete the basic principles of the existing standard [13].

\subsection{The Motives of SNI-certified Children's Toy Industries to Implement QMS}

This study has found that the motives of the four SNIcertified toy industries to apply QMS internally are similar, namely to improve product quality, efficient operational time, and quality management system itself and to reduce the number of product defects. These results correspond with [3];[12];[10];[21], all of which affirm that the primary internal reasons why certified companies implement QMS are that it can improve the internal process and procedure and increase product quality. As for the medium-scale toy industry, the major internal motive is this company's commitment. Interviews with respondents have revealed that the company's commitment to applying QMS is apparent from the management system review, which has been carried out to ensure regular compliance with the standards. These results are consistent with [22], which suggests that companies must correct all ineffective actions in preserving the certification they own. Strong commitment from top management produces positive impacts as it ensures the regular audits, revision, and improvement of QMS for the company's effectiveness [21]. The effectiveness of implementing and maintaining QMS is driven by a strong corporate culture [15].

The small-scale toy industries are motivated to use QMS because of two external motives, which are the government's facilitation for product certification and willingness to respond to the government's regulatory requirements. These are believed to be the underlying factors of the less effective QMS application, which is a determinant for the companies to receive a product certification. The companies observed in this study have yet to appoint staff to be responsible for proper QMS practices. QMS implementation is unfortunately carried out merely by the company's owners. This finding is in line with [3] that confirms approaches in QMS practices and the absence of staff's participation as the major problems within the company. In this situation, staff empowerment and effective communication from the company leaders are required for an effective QMS [15]. The goals, objectives, and functions of QMS in a company need to be determined and communicated by the company's leaders to build the required policies on product quality [23].

The external motives of the medium-scale toy industry stem from the necessity to maintain and increase product competitiveness and company image. Respondents are aware that product competitiveness depends on the quality of the products and will build the company's image indirectly. This image is thought to improve because the company has the proper quality system [24];[4]. High competitiveness is guaranteed through QMS implementation [3] because QMS directs the operation and includes all necessary processes to run the industry [25].

\subsection{Constraints in QMS implementation in SNI-certified children's toy industries}

Costs of implementation and certification are found to be a general obstacle that both small and medium-scale enterprises have to face. The application of standards within the company incurs additional financial expenses, confirming the previous finding, that is, certification complicates the company with its procedure and cost [12]. Business actors in small-scale toy industries present costs of an audit, complete documentation for certification requirements, and laboratory testing for products as a particular financial burden in implementing standards because they will permanently turn into the company's fixed costs. However, at the same time, product sales are not as significant as the money spent on this implementation. This finding supports [18] who suggests that costs of implementation and certification are the major obstacles in implementing standards in small-scale enterprises. Government policies are necessary for assisting business actors in toy industries in financing the costs of QMS implementation and certification. According to Blind (2016), encouragement for practical QMS application is required, for example, by establishing an appropriate 
support scheme for companies to participate in standardization as a public policy.

\section{CONCLUSION}

Previous studies have not thoroughly analysed the application of quality management systems in children's toy industries with SNI-certified products, particularly in smallscale enterprises. The findings in this research are in line with Prajogo (2015), which explains that holding certification does not necessarily show the quality of QMS application in the company. On the contrary, the mediumscale toy industry can implement QMS effectively because it has a standardization unit or department. Also, it believes that implementing QMS as a strategic step proves its commitment to improving the company's competitiveness and image. These results are consistent with Blind (2016), which confirms that companies with a standardization unit can act strategically in standardization.

The motives of certified toy industries to practice QMS are generally to improve product quality, efficient operational time, and quality management systems and to reduce the number of product defects. However, these enterprises face major obstacles in implementing QMS internally, including the costs for completing relevant documentation and quality system audit fees as a part of certification requirements. This finding is in line with Sommer (2007), which claims that companies perceive costs for adopting a standard as a constraint.

\section{ACKNOWLEDGMENTS}

The authors would like to thank the owners of the children's toy industries in the Special Region of Yogyakarta, Indonesia for their willingness to be the survey respondents in this study and the Muhammadiyah University of Magelang for their support during the completion of this research.

\section{REFERENCES}

[1] Vasileios Ismyrlis Odysseas Moschidis, "The effects of ISO 9001 certification on the performance of Greek companies: A multidimensional statistical analysis," TQM J., vol. 27 Issue 1 p, 2015.

[2] C. Lin, "An integrated framework for ISO 9000 motivation, depth of ISO implementation and firm performance," J. Manuf. Technol. Manag., vol. 19, no. 2, pp. 194-216, 2007.

[3] T. A. Salimova and V. I. Makolov, "Unused Potential of Quality Management Systems of the Russian Companies : an Empirical Study," Eur. Res. Stud., vol. XIX, no. 3, pp. 150-166, 2016.
[4] T. C. Keng and S. Z. Kamal, "Implementation of iso quality management system in construction companies of Malaysia," J. Technol. Manag. Bus., vol. 03, no. 01, pp. 1-23, 2016.

[5] F. Eli Kofi Aba M. Affan Badar Michael Allen Hayden ArticleAuthors, "International Journal of Quality \& Reliability Management," Int. J. Qual. Reliab. Manag., vol. 33, no. 1, pp. 1-23, 2016.

[6] B. Neyestani, "Effects of ISO 9001 on NonFinancial and Financial Performance in the Organizations : A Review,” 2017.

[7] A. Martin, "Research article iso 9001 impact on operational performance," Int. J. Recent Adv. Multidiscip. Res. Vol., vol. 04, no. 03, pp. 2407-2415, 2017.

[8] F. Dimitrios P. Kafetzopoulos, Evangelos L. Psomas, Katerina D. Gotzamani, ArticleAuthors, "The impact of quality management systems on the performance of manufacturing firms," Int. J. Qual. Reliab. Manag., vol. 32, no. 4, pp. 381-399, 2015.

[9] A. C. Phan, "ISO 9000 implementation and performance : empirical evidence from Vietnamese companies Anh Chi Phan Minh Hue Nguyen * Yoshiki Matsui," Product. Qual. Manag., vol. X, 2013.

[10] D. Drosos, M. Skordoulis, and M. Chalikias, "The Impact of ISO 9001 Quality Management System Implementation in Tourism SMEs," Proc. Bus. Econ., pp. 145-157, 2017.

[11] L. M. Fonseca and J. P. Domingues, "Empirical Research of the ISO 9001 : 2015 Transition Process in Portugal : Motivations, Benefits, and Success Factors," Qual. Innov. Prosper., vol. 1745, pp. 16-46, 2018.

[12] Sidonie Djofack Marco Antonio Robledo Camachor, "Implementation of ISO 9001 in the Spanish tourism industry," Int. J. Qual. Reliab. Manag., vol. 34, no. 1, pp. 18-37, 2017.

[13] C. Castillo-Peces, C. Mercado-Idoeta, M. Pradoroman, and C. Castillo-Feito, "The influence of motivations and other factors on the results of implementing ISO 9001 standards," Eur. Res. Manag. Bus. Econ., vol. 24, pp. 33-41, 2018.

[14] N. Nissinboim and E. Naveh, "Process standardization and error reduction: A revisit from a choice approach," Saf. Sci., vol. 103, no. November 2017, pp. 43-50, 2018.

[15] D. Willar, V. Coffey, B. Trigunarsyah, D. Willar, and V. Coffey, "Examining the implementation of ISO 
ISO 9001 quality management system effectiveness amongst electrical and electronics manufacturing firms in Malaysia," Int. J. Qual. Res., vol. 12, no. 3, pp. 655676, 2013.

[22] G. S. Oliveira et al., "Total Quality Management \& Business Excellence Investigation of TQM implementation: Empirical study in Brazilian ISO 9001-registered SMEs,” Total Qual. Manag. Bus. Excell., vol. 3363, no. May, pp. 0-19, 2017.

[23] J. Nenadal, “Adequacy, Suitability, Effectiveness and Efficiency of Quality Management Systems : How to Perceive and Assess them ?," vol. 1745, pp. 39-52, 2016.

[24] V. I. O. Moschidis and A, "The effects of ISO 9001 certification on the performance of Greek companies: A multidimensional statistical analysis," TQM J., vol. 27, no. 1, pp. 150-162, 2015.

[25] I. Adrianatisca, G. Cornu, N. Diaconu, and C. Dan, "Diagnosis, risk and efficiency in the implementation of TQM in small and medium enterprises," vol. 26, no. 15, pp. 215-218, 2015.

[21] M. R. Shaharudin, S. F. H. J. Akbar, N. R. N. A.

Rashid, N. Fatihah, and N. M. Noor, "Determinants of 